\title{
AS CRIANÇAS QUE VINGARAM: SETE FORMAS DE SER NEGRO NO BRASIL OITOCENTISTA
}

PINTO, Ana Flávia Magalhães. Escritos de liberdade: literatos negros, racismo e cidadania no Brasil oitocentista. Campinas: Editora da UNICAMP, 2018. 376p.

Anualmente, o Instituto Brasileiro de Geografia e Estatística (IBGE) divulga dados a respeito das desigualdades por cor no país. Em tempos de "pós-verdade", de ataque às instituições de pesquisa, de fake news divulgadas por fontes duvidosas, de convicções rápidas e não fundamentadas, mas que recebem status de verdades absolutas, é sempre bom lembrar que a desinformação oculta a forma como as desigualdades de hoje se vinculam às de ontem. De acordo com os dados disponibilizados pelo IBGE em 2019, os negros (soma de pretos e pardos) tornaram-se 55,8\% da população brasileira. Entretanto, as pessoas brancas permanecem recebendo os salários mais elevados, continuam sendo majoritárias entre o ocupantes dos cargos gerenciais e seguem tendo as taxas mais elevadas de frequência escolar em todas as idades. ${ }^{1}$

1 Instituto Brasileiro de Geografia e Estatística, Desigualdades sociais por cor ou raça no Brasil. Estudos e pesquisas. Informações demográficas e socioeconômicas,
Nenhuma dessas informações oferece novidade, dirão a leitora e o leitor desta resenha, diante do que parece ser uma ladainha monótona (quando divulgada pela imprensa) ou panfletária (quando ressaltada por militantes). É justamente para isso que quero chamar a atenção. Tais dados têm sido divulgados anualmente e, de tão persistentes, costumam ser tomados por banais. É brutal a normalidade com que muitos de nós, brasileiras e brasileiros, nos acostumamos a encarar essa desigualdade racial explícita e que não surgiu da noite para o dia. Nossa habitual indiferença diante das posições sociais bem delimitadas condiciona até mesmo a forma e o conteúdo do que vemos, quando olhamos para o passado. Não estamos acostumados a enxergar negros fora do lugar em nenhum momento de nossa longa história nacional.

Pois foi buscando romper a normalidade de nossa cegueira, ou seja,

Brasília: IGBE, 2019. 
desejando ver além dos fortes vínculos estabelecidos entre pele escura e escravidão, que a historiadora e professora da Universidade de Brasília, Ana Flávia Magalhães Pinto, publicou em 2019 a obra aqui resenhada. Resultado de sua tese de doutoramento, defendida na UNICAMP em 2014, trata-se do desfecho de uma pesquisa ampla e demorada, um livro muito bem escrito e fartamente documentado. Pude acompanhar pelas mídias sociais o empenho da autora em fazer a sua obra circular pelo país, em diálogo com os movimentos sociais, sobretudo os coletivos formados por mulheres e homens negros.

O livro está dividido em três partes. A primeira aborda as origens sociais e familiares de quatro letrados negros, as redes de relações nas quais estavam inseridos em São Paulo e no Rio de Janeiro, bem como uma parte de suas vidas até a década de 1880. Alguns mais, outros menos conhecidos pelo público, são eles José Ferreira de Menezes, Luiz Gama, José do Patrocínio e Machado de Assis. A segunda parte dá continuidade à análise da produção intelectual deles, agora conferindo mais atenção ao tratamento literário e jornalístico que aqueles homens de cor deram às principais transformações sociais de seu tempo, tais como o movimento abolicionista, a reforma eleitoral e os protestos populares. A última parte incorpora à análise novos nomes, tais como Ignácio de Araújo Lima, Arthur Carlos e Theophilo Dias de
Castro, e centra o foco nos conflitos por eles vividos após a Lei Áurea, destacando o associativismo negro, seus vínculos com o movimento operário e as divergências políticas internas às comunidades de cor, especialmente as tensas relações entre republicanos e monarquistas. Ao longo do livro, para além de revelar as ações e reações de vários outros personagens à distribuição desigual de direitos, o olhar da autora recai sobre sete intelectuais negros e as (nem sempre) diferentes formas como eles pensaram individualmente, agiram coletivamente $\mathrm{e}$ compartilharam identidades raciais no Brasil oitocentista.

O estudo de Ana Flávia Magalhães Pinto ataca certos pressupostos historiográficos persistentes. O primeiro a cair é a miopia a respeito do interesse e da participação negra nas questões mais sensíveis do final do século XIX, tais como o fim da escravidão, a derrocada do Império e o direito ao voto. Do início ao fim, o livro se dedica a demonstrar o protagonismo dos homens negros nos movimentos sociais que conduziram a nação ao 13 de maio e ao 15 de novembro. Portanto, abandone-se definitivamente a ideia de que abolicionistas e republicanos eram todos brancos. A autora desenvolve críticas respeitosas e bastante pertinentes às interpretações de José Murilo de Carvalho acerca da participação popular e negra no movimento republicano e nos processos eleitorais (pp. 298-300). Ainda que reconheça as evidentes restrições à cidadania, 
ela contraria não apenas as afirmações de que os trabalhadores negros e pobres "mantinham-se afastados da participação no governo da cidade [do Rio de Janeiro] e do país", como também as de que a "arraia miúda" não se considerava membro da República ou da Nação (p. 299). Na análise de Ana Flávia, os subalternos parecem não se encaixar muito bem na moldura dos bestializados.

$\mathrm{O}$ segundo pressuposto a ser derrubado é a ideia de isolamento e excepcionalidade dos intelectuais negros. Longe de atuarem apenas individualmente, preocupados com o próprio umbigo, os letrados "de cor" não apenas colaboravam uns com os outros - vejam-se as cartas trocadas entre Ferreira de Menezes e Luiz Gama (pp. 100-101) ou os elogios de Machado de Assis a Ferreira de Menezes (p. 43.) -, como também se preocupavam com os destinos de homens e mulheres que ainda não haviam saído da escravidão. Salta aos olhos a luta incansável e dramática de Luiz Gama, abolicionista precoce, promovendo ações de liberdade. Ao mesmo tempo, os letrados negros fizeram parte do amplo movimento associativo que caracterizou o final do século XIX, período no qual surgiram, em profusão, sociedades organizadas em torno da cor e da classe, preocupadas em oferecer instrução para garantir o exercício qualificado da cidadania, particularmente o voto, e assim interferir nos rumos políticos da nação.

O terceiro paradigma a ruir é a visão homogeneizante dos negros como um grupo coeso, unívoco, consensual. Ana Flávia descortinou a diversidade de orientações políticas no interior das comunidades formadas por pessoas de cor naquele período, divididas entre apoiar a Monarquia ou a República. E mesmo quando concordavam a respeito dos objetivos, poderiam discordar acerca da melhor forma de alcançá-los. Nem mesmo individualmente os sete personagens de Ana Flávia escaparam à fina detecção das suas contradições, já que outra qualidade da autora e de seu livro é apontar as incoerências de cada um deles.

A primeira parte da obra foi dedicada às trajetórias de Ferreira de Menezes, Luiz Gama, José do Patrocínio e Machado de Assis. A música e o teatro, a literatura e a imprensa despontam como espaços de diálogo, de conexão e de aproximação, ainda que eles vivessem em cidades diferentes. A historiadora demonstra intimidade com a literatura nacional produzida no período, além da produção daqueles letrados negros que estuda. Isso lhe permite interpretar a ficção literária com objetivo de compreender os autores, que demonstravam identificação com o mundo da política por meio dos enredos, das narrativas e dos personagens. Utilizando muito bem as ferramentas da história social, ela evidencia que as ficções literárias estavam fundamentadas nos contextos sociais em que aqueles negros viviam.

De todos os intelectuais analisados, a trajetória mais dramática 
parece ter sido a de Luiz Gama. Filho de um "fidalgo de origem portuguesa que se tomava por branco", cuja identidade permanece anônima, e da africana Luiza Mahin, Gama teria sido vendido como escravo pelo próprio pai em 1840 , aos 10 anos de idade (p. 88). Aprendeu a ler na casa senhorial e, desde muito cedo, reivindicou direitos de liberdade (p. 89). Foi trabalhando como copista e como amanuense que Gama se aproximou das leis. Entretanto, jamais conseguiu se formar em Direito, atuando a maior parte de sua vida como rábula (p. 86). Carregando no corpo as marcas visíveis da ascendência africana, Luiz Gama foi alvo do racismo institucional na Faculdade de Ciências Jurídicas de São Paulo (p. 87), assim como José do Patrocínio foi alvo do preconceito de cor quando tentou ingressar no curso de Medicina (p. 120). Desde a década de 1860, Gama esteve envolvido com a libertação de escravos, caracterizando uma atuação que exigia dele um amplo trânsito por associações emancipacionistas, partidos políticos, jornais e tribunais (pp. 92-93). A memória coletiva a respeito de suas habilidades jurídicas e de sua luta pela liberdade alheia fez com que Luiz Gama se tornasse um elo entre as experiências negras anteriores e posteriores ao $13 \mathrm{de}$ maio (p. 97).

O lugar social de onde Menezes, Patrocínio, Gama e Machado se projetaram era instável e precário (p. 33). Ana Flávia tomou o cuidado de verificar as dificuldades enfrentadas por eles tanto para obter acesso ao estudo quanto para se manter enquanto estudavam. Nas quatro trajetórias analisadas ainda na primeira parte do livro, a autora reconstitui com maestria as complexas redes de relações pessoais, de afeto, de proteção e de apadrinhamento necessárias para criar oportunidades de estudo e de trabalho, mas também capazes de limitar a atuação de sujeitos negros, por meio das expectativas de gratidão nutridas por pessoas que ocupavam a parte de cima das hierarquias políticas, econômicas e raciais. José do Patrocínio, por exemplo, obteve bolsa de estudos, emprego, casa e comida de muita gente. Em determinado momento da vida, teve de retribuir os auxílios que recebera da família chefiada pelo capitão Emiliano Rosa de Senna, tornando-se docente dos filhos do militar. Foi exercendo este ofício que Patrocínio enamorou-se da sua futura esposa branca, irmã de seus alunos (pp. 119-121).

Filho de um vigário de 54 anos e de uma jovem escravizada de 13 , Patrocínio não herdou a condição materna e cresceu livre desde a primeira idade (p. 115). Ana Flávia não comete aquele equívoco que Pierre Bourdieu chamou de "ilusão biográfica" ${ }^{2}$ e não explica o desenvolvimento posterior de seus personagens em função de suas origens, ainda que reconheça o peso

2 Pierre Bourdieu, "A ilusão biográfica", in Marieta de Morais Ferreira e Janaina Amado (orgs.), Usos e abusos da história oral (Rio de Janeiro: Editora da FGV, 1998), pp. 183-191. 
dos estigmas étnicos e raciais de possuir antepassados no cativeiro e pele escura (p. 117). Mesmo quando admite a infância como um importante momento de construção individual (p. 118), a autora privilegia o processo, as ações, as escolhas e as possibilidades limitadas impostas àqueles que almejavam ser protagonistas a partir "de baixo".

Todos os sete letrados tiveram intimidade com os jornais. Machado de Assis acreditava que a imprensa era instrumento indispensável para o exercício de um debate público capaz de transformar a sociedade (p. 147). E foi por meio da trajetória de Patrocínio que a imprensa despontou como espaço privilegiado e preferencial de atuação política e debates raciais executados por aqueles eruditos de pele escura. Nas linhas e páginas dos diários e hebdomadários, José do Patrocínio e Silvio Romero tiveram longas contendas sobre raça. Ana Flávia traz às leitoras e leitores do século XXI as imbecilidades escritas por Romero no século XIX, que, além de insistir na inexistência de civilizações africanas, chegava a afirmar que os egípcios eram brancos (p. 127). Simultaneamente, é por meio daquelas mesmas páginas que podemos conhecer o esforço intelectual de José do Patrocínio - bem como o de Luiz Gama, Ferreira de Menezes e Machado de Assis - para contrariar as teorias raciais importadas da Europa. Por meio de uma análise política do vocabulário racial, Ana Flávia nos convence de que aqueles intelectuais desenvolveram sentimentos de identidade comum, baseados tanto no entendimento político da raça quanto na percepção de que pretos e pardos eram os alvos centrais do racismo. Convém lembrar que Luiz Gama olhou para os brasileiros que não possuíam todos os critérios fenotípicos para figurar como brancos e registrou: "em todos há meus parentes" (p. 146).

Não é difícil perceber que, do início ao fim do livro, a historiadora confere maiores atenções àqueles letrados negros que, por conta de sua atuação política e produção intelectual, contaram e ainda contam com grande reconhecimento junto à memória coletiva nacional: José do Patrocínio e Machado de Assis. Patrocínio era ovacionado por negros e brancos na década de 1880; Machado, por sua vez, sempre teve comportamento reservado, destoando bastante dos outros intelectuais negros. A própria autora não esconde seu fascínio pelo bruxo de Cosme Velho. Nesse ponto, encontro um dos aspectos de que gostei menos deste fascinante livro. Incomoda-me a forma como alguns intérpretes do autor de Dom Casmurro e Memórias Póstumas de Brás Cubas justificam suas leituras e dialogam com seus leitores. Em alguns casos, é como se a falta de uma profunda estima e admiração obrigatória por Machado, bem como as discordâncias interpretativas sobre o escritor, fossem sinais de pouca inteligência ou de incapacidade de decifrar as geniais mensagens ocultas em seus 
escritos. Fica parecendo que é recusado o direito de criticar Machado, ainda que o compreenda. E a capacidade de decifrá-lo corretamente assume a forma de uma habilidade permitida a poucos iluminados. Vamos, então, à polêmica experiência racial de Machado.

Tendo por pai um pardo e por mãe uma açoriana (p. 151), Machado definitivamente não era um negro retinto. Era mestiço. Ana Flávia observa, acertadamente, que não era preciso ostentar uma cor azeviche na pele para ser obrigado a lidar com os constrangimentos raciais (p. 149). Mas também é verdade que, no Brasil daqueles dias, não era preciso ter uma aparência nórdica, cabelos loiros e olhos azuis para figurar como branco. Além disso, por meio de um diálogo com a historiografia, a autora critica com razão o mito de que "Machado de Assis quis se passar por branco" intencionalmente (p. 150). Por outro lado, o famoso literato preferia escrever acerca da experiência racial alheia, em terceira pessoa, não a respeito das suas próprias vivências, tanto que não revidou as acusações racistas feitas diretamente a ele por Silvio Romero (p. 169). Talvez o problema resida justamente nessa disputa pela atribuição de significados ao comportamento íntimo e subjetivo do autor. Sem importar os debates pós-raciais da historiografia norte-americana, convém chamar a atenção, não para o que Machado fez com a própria cor, mas para o que a sociedade brasileira, simultaneamente miscigenada e racista, poderia ou não fazer com a cor de Machado.

Nossa escadaria racial valoriza cada degrau epidérmico em direção ao padrão racial mais claro, ao mesmo tempo em que costuma recusar a inclusão dos pardos no grupo dos brancos. Precisamos entender mais e melhor a forma como eixos de vantagem interagem com eixos de subordinação, interferindo nas experiências de certos homens de cor que nem sempre eram classificados como negros pelos brancos. Soma-se a isso a demanda crescente por reflexões a respeito do fato de que aqueles negros eram homens, com vantagens sobre as mulheres de sua mesma condição racial. Talvez Machado de Assis pudesse ser reconhecido por outras pessoas como alguém que transitava nos dois lados da linha de cor, independentemente de sua vontade. Nem toda classificação racial é inequívoca, particularmente no que diz respeito a mestiços, e somente Machado sabia quais eram as dores e as delícias de ser o que era. Trata-se de afirmação polêmica e que, portanto, não esgota o debate; mas insisto que o racismo não condiciona sempre da mesma forma e nem sempre com a mesma intensidade as experiências de todas as pessoas "de cor" (hoje em dia, as mulheres negras, por exemplo, ganham menos do que os homens negros no mercado de trabalho). Por outro lado, exatamente da mesma forma como os demais letrados presentes neste estudo, Machado 
precisou de muita ajuda na vida e foi apadrinhado pelo tipógrafo e editor negro Francisco de Paula Brito (p. 153). Sinal de que sua cor parda não lhe dava grandes vantagens.

$\mathrm{Na}$ segunda parte de seu livro, Ana Flávia busca problematizar os lugares sociais ocupados por negros livres e libertos ao longo da última década do escravismo, com destaque para a forma como eles elaboraram propostas para resolver os dilemas da sociedade em que viviam. Destaca-se aí o protagonismo negro no processo que resultou na Revolta do Vintém no Rio de Janeiro, em 1879. Produto do acúmulo de tensões sociais, o levante indica que transporte, moradia e alimentação já eram problemas graves na segunda metade do século XIX (p. 189). Num contexto em que trabalhadores negros e pobres não eram reconhecidos como cidadãos aptos ao exercício do voto, mas eram obrigados a pagar impostos, a elevação do preço da passagem do bonde foi a gota d'água que faltava para mobilizar os estratos subalternos da Corte. Revelam-se, então, certas ambiguidades dos eruditos de pele escura. Ferreira de Menezes era abolicionista convicto e favorável à ampliação do corpo eleitoral, sintonizado com os anseios dos trabalhadores da cidade, que davam sinais evidentes de que viam a si mesmos como cidadãos (p. 193). Contudo, ele organizou um grupo de letrados, advogados, médicos, membros dos três únicos partidos - Republicano, Liberal e Conservador - com a finalidade de intervir na revolta e "aconselhar o povo" (p. 199-202). Ou seja, em um momento de tensão política, Menezes recorreu a membros das elites para intervir sobre o protagonismo dos "de baixo".

Ainda na segunda parte da obra, Ana Flávia reconstitui as disputas jurídicas levadas a cabo por abolicionistas negros incansáveis em denunciar a escravização ilegal. A análise dos argumentos utilizados indica a forma como a legislação emancipacionista poderia ser interpretada e usada em favor dos escravizados: a partir da Lei de 1831, todos os escravos eram ilegais; depois da Lei do Ventre Livre, estava proibida a venda e a separação da família; em 1882, ficou proibido o tráfico interprovincial. Ao mesmo tempo, a autora identificou diversos casos de escravização ilegal durante a década de 1880 , apontando para a precariedade estrutural da liberdade no Brasil daquele tempo. Em linhas gerais, ela descreve um cenário em que a colaboração entre os abolicionistas de diferentes províncias, durante a década de 1880, ficou quase sempre restrita às cidades de São Paulo e Rio de Janeiro. Preciso advertir que esta não é uma característica encontrada somente no estudo de Ana Flávia Magalhães Pinto. Trata-se de um hábito historiográfico persistente, em que as cidades do Rio de Janeiro e São Paulo são tomadas como representativas da nação, verdadeiros centros definidores de sentido para a história do Brasil, o que conduz a um escasso diálogo entre 
as pesquisas a respeito do Sudeste e as investigações acerca de outras regiões do país. Nesse sentido, fazem falta ao estudo de Ana Flávia maiores apontamentos sobre a interlocução estabelecida entre os abolicionistas situados muito além de Rio de Janeiro e São Paulo. Há bastante tempo, Silvia Petersen já havia chamado atenção para a necessidade da história social olhar mais e melhor para os diálogos estabelecidos entre subalternos que viviam em diferentes cidades do país durante $\mathrm{o}$ final do século XIX e o início do XX. ${ }^{3}$

A última parte do livro de Ana Flávia volta-se para o pós-abolição, centrando a análise nas formas como os letrados negros reagiram ao racismo e às restrições ao exercício da cidadania. Surgem, então, os nomes de Arthur Carlos, Ignácio de Araújo Lima, Theophilo Dias de Castro e outros. Por aqueles dias, a imprensa negra de São Paulo expressava forte senso de identidade com base na cor e defendia a unidade racial entre pretos e pardos, já colocados em um "mesmo repositório de sentidos", na expressão de Ana Flávia (pp. 271-272). O fio condutor da narrativa recai, então, sobre o trânsito daqueles homens por espaços urbanos conhecidos na historiografia como "territórios

3 Silvia Regina Ferraz Petersen, "Cruzando fronteiras: as pesquisas regionais e a história operária brasileira", in Ângela M. C. Araújo (org.), Trabalho, cultura e cidadania: um balanço da história social brasileira (São Paulo: Scritta, 1997), pp. 85-103. negros", evidenciando sua proximidade e sua inserção no associativismo negro e operário. A autora identifica também certos aspectos religiosos da atuação dos letrados negros; Theophilo Dias de Castro, por exemplo, era integrante da Irmandade de Nossa Senhora do Rosário dos Homens Pretos. Para a autora, "a fé cristã aproximava e explicava uma parte daquela união" (p. 278).

É praticamente impossível ler uma análise sobre a forma como homens negros reagiram ao racismo sem se perguntar, afinal, onde estavam as mulheres negras. Olhar para os embates políticos do final do século XIX e enxergar os homens não informa sobre uma escolha da autora de fechar seus olhos para as experiências de mulheres negras. Informa a respeito da forma como aqueles homens se relacionavam com as mulheres da mesma cor. Em 2018, durante o II Seminário Internacional Pós-Abolição no Mundo Atlântico, Ana Flávia declarou publicamente que foi com as mulheres negras que aprendeu a pensar. De fato, a autora não deixou de vê-las, já que identificou Cecílias, Joanas, Lúcias, Justinas, Marias, Antônias e Leopoldinas em uma associação negra do período (p. 312). Além disso, ao analisar uma escola noturna direcionada para "pessoas do sexo masculino", Ana Flávia denunciou "a facilidade com que [os homens negros] reproduziam as desigualdades de gênero", agindo em favor do 
"empoderamento deles próprios" e contribuindo para a "subalternização feminina negra" (p. 319).

Se, a partir de 14 de maio de 1888 , muitos senhores ficaram frustrados, esperando uma indenização que nunca chegou, também é verdade que a população de cor estava decepcionada. Além dos critérios legais para votar, tais como a exigência de uma solicitação por escrito e a assinatura do votante, o exercício da cidadania dependia também de boas relações com as autoridades. Ana Flávia identificou perfeitamente as brechas nas leis eleitorais do Império e da República capazes de serem manipuladas com o intuito de ampliar ou restringir o eleitorado, mas também capazes de alimentar as expectativas em relação à participação popular nos rumos da política nacional. Sim, havia trabalhadores negros e pobres reconhecidos como eleitores. Este é o momento do livro em que a autora ressalta várias vezes que a população negra havia depositado suas esperanças na Lei Áurea, na República e na ampliação da cidadania.

Após 376 páginas, o livro de Ana Flávia chega ao fim apresentando às leitoras e leitores certa metáfora melancólica. "Nem todas as crianças vingam" é expressão encontrada em uma crônica de Machado de Assis (p. 344), e diz respeito ao fato de que nem todas as expectativas acerca da liberdade foram alcançadas.

Escritos de liberdade é obra de leitura indispensável não apenas para nos ajudar a compreender a sociedade brasileira e as disputas pela definição dos seus rumos durante os anos anteriores e posteriores à lei de ouro, mas também para resgatar do silêncio e do esquecimento personagens de pele escura cuja atuação coletiva buscou derrubar barreiras, diferenças e desigualdades que, em grande medida, seguem até hoje (como indicam as estatísticas divulgadas anualmente pelo IBGE). A título de exemplo, cito a mobilidade social no Brasil, que permanece muito mais ampla para os brancos (que podem ser encontrados em todos os andares do edifício social), do que para os negros (presentes majoritariamente nos andares mais baixos). O dramático interesse de mulheres e homens negros pelas temáticas e debates públicos fundamentais daqueles dias - a emancipação e a República, o trabalho livre e a instrução qualificada, o direito ao voto e à vida associativa - desautorizam interpretações que não os levem em conta como protagonistas fundamentais, capazes de pensar e atuar por si mesmos. Contudo, se é verdade que nenhuma sociedade é tão opressora que nunca tenha deixado margem de ação para os sujeitos subalternos, também é verdade que não existem sujeitos tão livres que nunca tivessem sofrido algum tipo de constrangimento. O tamanho das esperanças e expectativas nutridas pela multidão de cor acerca da cidadania e da vida em liberdade, aspectos bem ressaltados por Ana Flávia em seu estudo, foram proporcionais ao tamanho 
da frustração diante da realidade política instaurada a partir do $13 \mathrm{de}$ maio e do 15 de novembro. Quero crer que Ana Flávia e Machado de
Assis concordariam comigo: o passado pode ser simultaneamente esperançoso e desanimador. Afinal, nem todas as crianças vingam.

Marcus Vinicius de Freitas Rosa Universidade Federal do Rio Grande do Sul marcuviniciu@gmail.com 